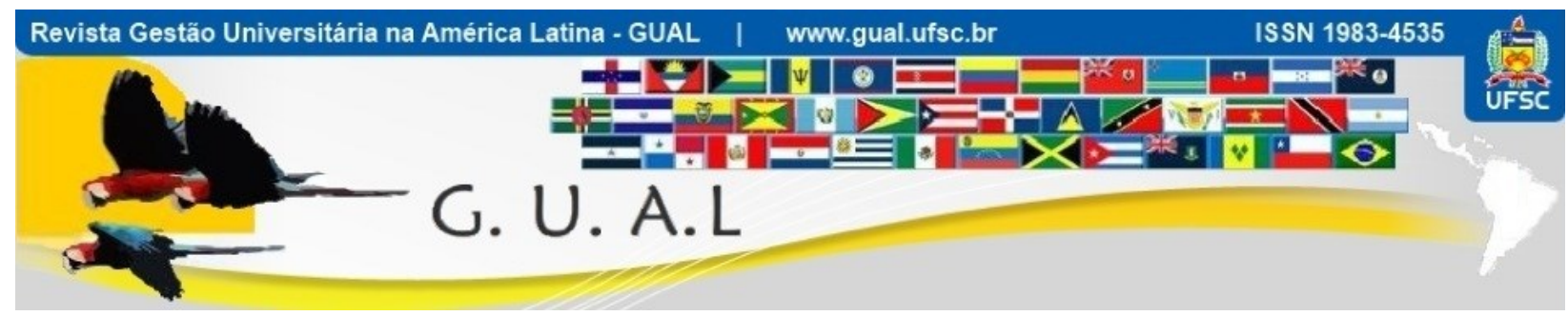

DOI: http://dx.doi.org/10.5007/1983-4535.2017v10n2p134

\title{
LIMITES DA DIGNIDADE DOS DOCENTES NAS PRÁTICAS DE GESTÃO EM UNIVERSIDADES BRASILEIRAS
}

\section{LIMITS OF DIGNITY OF TEACHERS IN MANAGEMENT PRACTICES IN BRAZILIAN UNIVERSITIES}

\author{
Ana Lúcia Medeiros, Doutora \\ Universidade Federal do Tocantins - UFT \\ analucia@,uft.edu.br \\ Maria Luisa Mendes Teixeira, Doutora \\ Universidade Presbiteriana Mackenzie \\ malluluisa@gmail.com
}

Recebido em $02 /$ novembro/2015

Aprovado em 12/dezembro/2016

Sistema de Avaliação: Double Blind Review

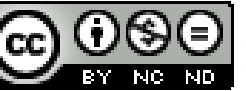

Esta obra está sob uma Licença Creative Commons Atribuição-Uso. 


\title{
RESUMO
}

O objetivo deste artigo é analisar como as práticas de gestão mediadas por relações sociais em universidades brasileiras refletem a dignidade dos docentes. As relações de produção são permeadas por conflitos entre trabalhadores e gestores, envolvendo questões de poder, conhecimento e a necessidade de tornar as organizações mais produtivas. A metodologia utilizada para alcançar o objetivo proposto foi de natureza qualitativa, mediante entrevistas em profundidade realizadas com docentes que atuam nestas universidades. Foi possível mapear as ausências e emergências e identificar que respeito, autonomia e dignidade apareceram em alguns relatos como ausências em universidades privadas, devido à lógica produtivista predominante.

Palavras-chave: Ausências. Dignidade. Docentes.

\begin{abstract}
The purpose of this article is to analyze how management practices mediated by social relations in Brazilian universities reflect the dignity of teachers. The relations of production are permeated by conflicts between workers and managers, involving power issues, knowledge and the need to make the most productive organizations. The methodology used to achieve the proposed objective was the qualitative approach, through in-depth interviews conducted with teachers who work in these universities. It was possible to map absences and emergencies and identify that respect, autonomy and dignity appeared in some reports as absences in private universities, because of the prevailing productionist logic.
\end{abstract}

Key-words: Absences. Dignity. Teachers. 


\section{INTRODUÇÃO}

Estudos relativos à dignidade humana vêm ganhando espaço no campo das Ciências Sociais, e, em especial, entre aqueles que pesquisam os assuntos orientados para as organizações. No Brasil, esse tema recebeu atenção especial dos pesquisadores da área do Direito, da Filosofia, e, por último, dos estudiosos da área de gestão de pessoas e teoria das organizações. Há uma grande quantidade de investigações direcionadas para o assédio moral e os direitos dos trabalhadores nas organizações (FREITAS 2001; HELOANI, 2004;) e para a dignidade organizacional (TEIXEIRA, 2008; MARGOLIS, 1997).

Boa parte dos estudos sobre dignidade nas organizações colocam como elemento central do debate a dignidade dos trabalhadores e de organizações bancárias, fábricas e empresas dos mais diversos ramos, especialmente, as de natureza privada. Neste trabalho será analisada a dignidade do docente do ensino superior em universidades brasileiras, porque se percebeu que a exemplo de outros trabalhadores que atuam em diferentes empresas e do professor da educação básica, esse profissional está enfrentando um processo de precarização nas relações de trabalho em universidades brasileiras (BOSSI, 2007).

Compreende-se que esse processo está associado à expansão do ensino superior no Brasil, principalmente de faculdades particulares e, nos últimos anos, de universidades públicas. Há um grande grupo de pessoas que ainda não teve acesso ao ensino superior e outro maior que irá entrar no sistema de ensino superior no país em decorrência da universalização do ensino médio no Brasil e da garantia dos direitos sociais adquiridos na constituição de 1988.

Pode-se dizer que há uma grande demanda em potencial por serviços universitários, e a universidade, que já foi considerada mansão do saber, encontra-se hoje submetida a regras, normas e controle orientados para a regulação das práticas de ensino na graduação, na pósgraduação, na pesquisa e na gestão (CHAUI, 2003; LEDA, 2006). Acredita-se que esses mecanismos pressionam a força de trabalho dessas organizações, o que é sentido especialmente pelos docentes, que são submetidos a uma intensa jornada de trabalho, quer em sala de aula, quer associada à pressão para produção de artigos científicos, de orientação de monografias, de dissertações de mestrado, de teses de doutorado, de pareceres e de participação em comissões, além da participação na gestão universitária (BOSSI, 2007).

O Estado, por sua vez, contribui para que as relações de trabalho sejam cada vez mais precárias e intensas, por implantar mecanismos de avaliação das universidades e dos docentes 
a partir de uma lógica de natureza instrumental, ao invés de substantiva (CARAN et al., 2010). Entendemos que essas questões colocam os docentes de universidades brasileiras em situação de vulnerabilidade e de precarização nas relações de trabalho, que são orientadas pelas filosofias e práticas de gestão que produzem ausências e invisibilidades nos processos de produção e de trabalho das organizações.

O espaço universitário, além de ser de produção e de troca de conhecimentos e de saberes, é também um ambiente organizacional regulado por normas e saberes prédeterminados a partir dos pressupostos da ciência moderna. É, portanto, um campo fértil para o estudo relativo ao direito, ao assédio moral e à dignidade do docente. Para este estudo foi utilizado o pensamento de Boaventura Sousa Santos, pelo fato de ele ter apresentado uma nova perspectiva epistêmica que pode ser usada para a compreensão da realidade social, compreendendo-a não apenas pelo o que ela é, mas, sobretudo, o que ela poderá ser.

No que se refere às relações de trabalho estabelecidas em universidades brasileiras, é possível inferir que as mesmas também são pautadas por critérios regulatórios, tendo em vista que a educação passou a ser concebida como mercadoria por uma grande parte de universidades e faculdades particulares que são geralmente orientadas para o lucro (DIAS SOBRINHO, 2005; SOUSA SANTOS, 2005b). Nesse sentido, defende-se a tese de que há produção de ausências, de presenças e emergências de dignidade dos docentes nos espaços de gestão em universidades brasileiras.

Considerando esse propósito, este artigo propõe-se a investigar a seguinte questão: Como as práticas de gestão mediadas por relações sociais em universidades brasileiras refletem a dignidade dos docentes?

O objetivo geral é analisar como as práticas de gestão mediadas por relações sociais em universidades brasileiras refletem a dignidade dos docentes.

Espera-se que esse trabalho contribua para que as universidades realizem uma gestão cujas práticas sejam norteadas por relações sociais emancipadoras e dignas. A título de contribuição teórica acredita-se ser possível usar o pensamento de Boaventura Santos para analisar os fenômenos organizacionais à luz da sociologia das ausências e das emergências.

\section{ILUMINANDO OS ESTUDOS ORGANIZACIONAIS A PARTIR DE UM PARADIGMA CONTRA HEGEMÔNICO}

A base teórica desse trabalho está assentada no pensamento de Sousa Santos que propôs o paradigma emergente cujos pressupostos são contra-hegemônicos. O paradigma 
dominante, ou hegemônico, ao contrário da proposta de Sousa Santos, sustenta-se na racionalidade ocidental e em princípios universalistas e deterministas. A racionalidade ocidental vigente, subsidiadora do sistema capitalista de produção, apresenta-se como razão metonímica e proléptica. A primeira se reivindica como a única forma de racionalidade, e a segunda "não se aplica a pensar o futuro, porque julga saber tudo a respeito dele" (SOUSA SANTOS, 2010a, p. 96).

Como proposta alternativa a essa epistemologia, Sousa Santos se encarregou de apresentar as sociologias das ausências e das emergências para dar voz ao que a razão metonímica traduz como não existente, para "transformar objetos impossíveis em possíveis e com base neles transformar as ausências em presenças" (SOUSA SANTOS, 2010a, p. 102). No que tange à sociologia das emergências, o autor busca apontar alternativas que caibam no horizonte das possibilidades concretas, posto que com ela se "produz experiências possíveis, que não estão dadas porque não existem alternativas para isso, mas são possíveis e já existem como emergência" (SOUSA SANTOS, 2007, p. 38).

Sousa Santos $(2007 ; 2010 a ; 2009)$ usa as expressões ausência e emergência para mostrar que a ciência moderna, ao se assentar sobre as monoculturas, desencadeou um processo de produção de não-existências e de ausências. Segundo ele (SOUSA SANTOS 2009; 2006; 2010; 2004), o mundo necessita de uma epistemologia que tenha como objetivo não apenas o fazer ciência com prudência, mas que também possa gerar uma vida decente.

Para tanto, deve-se levar em consideração a ética, o meio ambiente e reconhecer os diferentes saberes e direitos da coletividade. É necessário incorporar os saberes dos diferentes povos, o que requer dos pesquisadores incorporar diferentes métodos de investigação para que possam ter uma maior compreensão da realidade, uma vez que as relações sociais estabelecidas nos processos produtivos geralmente são pautadas por relações de trabalho regulatórias, ao invés de emancipatórias e dignas (SOUSA SANTOS, 2009; 2010).

Ao se produzirem a partir desse modelo padronizado, aumentam-se as possibilidades dessas organizações silenciarem os saberes e práticas sociais alternativos, porque elas foram concebidas e alicerçadas nas monoculturas, principalmente às relativas ao rigor científico, ao tempo linear, à classificação social e à produtividade mercantil e do trabalho (SOUSA SANTOS, 2007). Tais monoculturas se encarregaram de produzir ausências no espaço estrutural das organizações produtivas, e foram capazes de tirar de cena ou despontencializar todos aqueles que não se adequavam às regulações dessas unidades de práticas sociais. Pode- 
se dizer que nesse processo ocorreu um desperdício de experiências sociais (SOUSA SANTOS, 2006; 2009a; 2010a).

Esse desperdício pode ser concebido como as não-existências ou ausências promovidas pelas monoculturas que ao longo do tempo se encarregaram de produzir várias formas de inexistências. A monocultura do saber e do rigor produziu a primeira forma de inexistência ou de ausência que foi a ignorância, ou, dito de outro modo, todos aqueles que não foram socializados a partir da lógica do saber e do rigor científico é considerado pela sociedade como indivíduos ignorantes (SOUSA SANTOS, 2006; 2009a). Conforme Sousa Santos (2009a; 2005; 2006), sob a égide do paradigma da modernidade os saberes não reconhecidos pela ciência são chamados de saberes ignorantes, ou de senso-comum, isso por não estarem na base do racionalismo instrumental.

A segunda forma de inexistência ou de ausência foi promovida pela monocultura do tempo linear. Tudo que estivesse fora da concepção de progresso, desenvolvimento e modernização era chamado de primitivo, simples e selvagem (SOUSA SANTOS, 2006; 2009a). À sua maneira, a monocultura da naturalização das diferenças produziu uma ausência chamada de inferior, pois aqueles que não eram reconhecidos pelas suas diferenças eram concebidos como indivíduos inferiores e, para clarificar, no Brasil, serve como exemplo, o tratamento dado pelo Estado e pela sociedade à etnia indígena, aos homossexuais e aos grupos chamados de minorias.

A quarta forma de produção de não existência foi produzida pela monocultura da escala dominante e, aí, as ausências promovidas foram o particular e o local. Com o processo de universalização ou de globalização, os fenômenos locais foram descredibilizados e perderam a sua importância e, por fim, a monocultura do produtivismo capitalista, que produziu a forma de não existência ou uma ausência chamada de improdutivo ou preguiçoso. Todos aqueles que não estivessem aptos a ingressarem na lógica produtiva norteada pela racionalidade instrumental eram invisíveis frente a essa concepção.

É sob a luz dessa racionalidade que o pensamento de Sousa Santos dará base para que se compreendam as diferentes concepções de dignidade. A contribuição desse pensador a essa temática está associada à forma como ele percebe o mundo, sob uma perspectiva contrahegemônica e cosmopolita a partir do princípio da diferença e da igualdade. $\mathrm{O}$ reconhecimento dos direitos e dos saberes da coletividade abre espaço para que o 
conhecimento científico, assim como a lógica produtivista, se distancie da monocultura do saber e do rigor cientifico e do produtivismo capitalista, respectivamente.

O crítico concebe a emancipação e a dignidade humana sob a perspectiva das ecologias, dos reconhecimentos dos saberes e dos direitos sob a ótica do multiculturalismo. É possível inferir que ele defende a necessidade de se estabelecer um diálogo intercultural sobre a dignidade humana e que, a partir dela, se tenha uma compreensão mestiça de direitos humanos (SOUSA SANTOS, 2009a). Na linha de pensamento de Sousa Santos (2010a), para uma nova concepção da emancipação necessita-se da criação de um novo senso comum político que esteja ancorado no pilar da solidariedade, no princípio da comunidade, na ideia de autonomia e de um nascimento de uma nova cidadania. Essa, por sua vez, constitui-se na obrigação vertical entre os cidadãos e o Estado, bem como na obrigação política entre cidadãos (SOUSA SANTOS, 2007; 2002; 2005a). Pode-se perceber que o autor entende que há a necessidade do estabelecimento de uma cultura democrática de alta intensidade e que possa se constituir em um novo modelo de cidadania.

Ainda nas pisadas do pensador, esse processo democrático só ocorrerá por meio da sua radicalização, que se dá pela substituição das relações de poder por relações de autoridade compartilhada. Essa, por seu turno, para se concretizar necessita de ser respaldada pelo princípio do reconhecimento da diferença (SOUSA SANTOS, 2007; 2006; 2010a). Julga-se, contudo, que o pensamento de Sousa Santos aspira a um novo processo de organização social e a um novo modelo de convivência coletiva, que poderá exigir dos indivíduos novas alternativas para se viver a vida, para a organização do trabalho, da produção e para o fazer científico (SOUSA SANTOS, 2007).

\section{DIGNIDADE ORGANIZACIONAL: UM CONCEITO EM CONSTRUÇÃO}

No que se refere à concepção da palavra dignidade, pode-se dizer que existe uma grande controvérsia em torno de seu conteúdo. Geralmente, parte-se do pressuposto de que ela diz respeito à condição humana, guardando, pois, uma relação próxima com as complexas e imprevisíveis manifestações da personalidade humana (SARLET, 2009). Segundo Pereira (2006), existem duas concepções de dignidade, uma alicerçada nas características externas que envolvem o ser humano, como a proposição social, a hierarquia, a herança familiar; e outra, em que aparece a dignidade como atribuída e inerente à espécie humana e, portanto, universal. 
A partir das diferentes percepções acerca da dignidade humana, entra em cena a necessidade de se discutir a dignidade nas organizações uma vez que o trabalho passou a ser a força motora do desenvolvimento das nações. O trabalho, é, portanto, nas palavras de Marx, a principal mercadoria do trabalhador ou daquele ser humano desprovido dos meios de produção. Sendo assim, as relações produtivas e as de trabalho passaram a ser os dois lados da mesma moeda, ou seja, não há como ter produção sem a interação entre os próprios trabalhadores e entre estes e os capitalistas ou seus representantes.

Essas relações sociais, ao longo do tempo, se apresentaram sob a égide da exploração daqueles que detêm os meios de produção ou o poder da gerência sobre aqueles que se apresentam apenas como trabalhadores dispostos a vender a sua força de trabalho. A exploração do trabalho se dar por meio de práticas de gestão que se encarregam de gerar mais-valor e aumento de desempenho, cuja finalidade, nos dizeres de Marx, é aumentar a competitividade das organizações que as levam a produzir mais-valor e reproduzir de forma ampliada o capital.

Ao compreender que as relações de trabalho e de produção são relações sociais e que elas acontecem no interior das organizações, entende-se que a organização pode ser vista como ator social. É a partir dessa perspectiva que Teixeira (2008) e Margolis (1999) entendem que é possível empreender estudos que busquem entender se há dignidade organizacional nas empresas. Nas pisadas das autoras, há que investigar o que e como seria uma organização digna. O conceito de dignidade organizacional, segundo Teixeira (2008), consiste nas relações sociais necessárias aos processos de produção e de trabalho dentro e fora das organizações e que devem ser pautadas pela ação comunicativa onde não há intenção de usar o outro para o alcance dos próprios fins.

Quando se analisa as organizações sobre a perspectiva das relações de trabalho, o que se percebe é que o trabalhador é usado no processo de produção apenas como meio para se atingir os objetivos organizacionais que não são necessariamente os seus, mas, dos donos e dos gestores da organização. O que os estudiosos das teorias organizacionais têm questionado em seus trabalhos é que as práticas de gestão e a incorporação da cultura do management é uma grande aliada das organizações por ter criado uma meio de gerir pessoas essencialmente gerencialista, o que, via de regra, avilta a dignidade do trabalhador (AKTOUF, 2001; MOTTA, 1984; TRÉPO, 1994). 
Boaventura de Sousa Santos compreende que a concepção de dignidade humana está embasada no princípio da igualdade e da diferença, o que quer dizer, que as pessoas têm o direito a ter direitos, bem como, ter seus saberes reconhecidos (SOUSA SANTOS, 2010a). Sob esse olhar, é possível encontrar alternativas para a partir de uma nova epistemologia, baseada em uma ecologia de saberes, direcionar luzes para que se possa compreender a dignidade organizacional.

Antes mesmo de discutir o conceito de dignidade organizacional em Boaventura Santos, se faz necessário entender que nas organizações o poder é exercido por meio do direito da produção de um lado e do trabalho do outro. Além disso, o poder também se faz presente por meio da gaiola de ferro que se encarrega de encarcerar outros saberes de gestão.

O saber hegemônico, que é aquele empregado nas organizações e que corresponde ao management, é, portanto, reconhecido cientificamente como o único capaz de garantir o processo de reprodução do capital e de gerar mais valor. Fora dessa linha, qualquer alternativa de incorporação de novas práticas de gestão concebidas para emancipar ou dignificar o trabalhador não são reconhecidas pela grande maioria das organizações capitalistas. Nesse sentido, o gerenciamento das pessoas, enquanto técnica para combinar estes recursos ao capital, é, ainda essencial, pelo menos até onde for necessário a existência de pessoas no processo de produção.

A presença de atores sociais (trabalhadores) na produção de mercadorias e serviços em qualquer organização, seja ela pública ou privada, demandará a implantação de práticas de gestão, até mesmo em universidades que é uma instituição diferenciada que não oferta um produto específico para o mercado, mas, que também obedece a uma lógica de organization e de management.

Nestas organizações que não são essencialmente produtoras de mercadorias são imputadas aos trabalhadores as mesmas regras do direito da produção e os mesmos saberes de gestão monocultural e hegemônico que são produtores de invisibilidades e de ausências de dignidade desta classe.

Ao patrocinar a proposta de que é possível tornar presentes todas as invisibilidades, e, em especial aquela associado à monocultura produtivista, a teoria de Sousa Santos é capaz de propor um modelo alternativo para analisar as relações de trabalho nas organizações. O mesmo poderá ter como arrimo pressupostos contra-hegemônicos e, portanto, baseado nas ecologias que buscam criar inteligibilidades e credibilizar os diferentes saberes e práticas 
sociais. Entendemos que isso não inviabiliza a existência das organizações do trabalho e da produção enquanto unidades que constituem o sistema capitalista de produção. A proposta do crítico português é apresentar um modelo que possa fazer emergir novos saberes e práticas a partir de uma nova relação entre a igualdade e o princípio do reconhecimento da diferença, ou seja, respeitar a capacidade que os indivíduos têm de ter direitos (SANTOS, 2009a; 2010a).

Podemos dizer que, partindo dessa concepção, as organizações do trabalho e da produção poderão encontrar meios que garantam a dignidade humana, a inclusão social e a autodeterminação e que tenham o objetivo de potencializar a liberdade e emancipação nas suas relações de trabalho. Nesse sentido, a exploração enquanto forma de poder presente no espaço da produção poderá ceder lugar a outras formas de poder, assim como também o poderá a monocultura da produtividade do trabalho e mercantil em relação a uma ecologia produtivista centrada em outras formas de produção e em outros modelos de gestão.

Esperamos, assim, que o pensamento de Sousa Santos possa contribuir para mostrar que as organizações, enquanto um espaço de produção e de relação de trabalho, possam ser capazes não apenas de facultar visibilidade às ausências que são refletidas nas práticas sociais, mas também de fomentar as emergências que podem ser visualizadas nas mesmas práticas.

Por essas razões, parece acertado afirmar, na esteira de Sousa Santos, que: dignidade é um processo de emancipação mediante o respeito aos princípios da igualdade e da diferença, do reconhecimento dos diferentes saberes e direitos que são projetados nos espaços estruturais - doméstico, comunidade, produção, mercado, cidadania e mundo [grifo da autora].

\section{PERCURSO METODOLÓGICO}

A pesquisa é de natureza qualitativa e a técnica utilizada para analisar os dados foi a análise de conteúdo de Bardin (2009). As categorias de análise destacadas neste estudo consistem em ausências e emergências refletidas nas práticas de gestão em universidades brasileiras.

Neste trabalho as ausências são compreendidas como aquelas práticas em que o paradigma hegemônico tratou de produzir como não-existências. Por outro lado, as emergências são aquelas que são colocadas em prática pelos sujeitos numa perspectiva da contra-hegemonia (SANTOS, 2010; 2006). 
Os dados foram coletados por meio de 12 entrevistas em profundidade aplicadas a docentes que atuam em instituições de ensino superior (universidades públicas, faculdades privadas e em universidades privadas e confessionais).

A título de caracterização do público alvo da pesquisa pode-se dizer que do grupo entrevistado, três são mulheres (P1, P2, P3), doutoras e atuam em universidades federais, privadas e confessionais no Brasil com mais de dez anos de experiência em docência no ensino superior em cursos de administração de empresas e economia. Os demais são homens (P4, P5, P6, P7, P8, P9, P10, P11, P12), com formação e titulação heterogêneas (especialistas, mestres, doutores e pós-doutores). Atuam em universidades públicas e privadas no Brasil e têm mais de cinco anos de experiência em docência do ensino superior em cursos de administração de empresas e economia.

O tratamento dos dados foi feito à luz do pensamento de Boaventura Santos. Optou-se por esta abordagem, porque se acredita que ela é apropriada para responder ao problema de pesquisa.

A luz do pensamento de Boaventura Santos e, em especial, considerando as categorias sociológicas apontadas por este autor - ausências e emergências -, é possível dizer que as encontradas têm conteúdo substantivo e que podem ser caracterizadas como ausências e emergências nas práticas de gestão em universidades brasileiras.

O processo de categorização ocorreu a partir da pergunta norteadora feita aos docentes que foi como eles percebiam a gestão da universidade a que estavam ou estiveram vinculados? A entrevista não seguiu um roteiro estruturado e isso fez com que no decorrer do processo fosse possível ajustar o mapa mental ao fenômeno estudado.

Para compreender os dados e orientar a discussão dos mesmos se fez necessário retomar as discussões sobre as categorias sociológicas ausências e emergências, presentes na obra de Boaventura Santos. Estas se revelam em diversos campos sociais ou espaços estruturais (Estado, comunidade, produção, mundo e mercado) (SANTOS, 2006).

Neste artigo, as categorias foram extraídas a partir da compreensão que os docentes tinham das relações de trabalho que ocorriam nos seus espaços de trabalho - universidades -. Este, é, como já foi dito, um espaço de produção, no caso em epígrafe, produção de conhecimento. Entende-se, portanto, que em organizações dessa natureza nem toda forma de poder se dar por meio da exploração, porém, toda a forma de gestão é orientada por todas ou 
algumas destas características: produtivismo, tecnologismo, formação profissional e cultura empresarial (SANTOS, 2009).

O espaço da produção é o local onde ocorrem as práticas sociais - de gestão -, que são consubstanciadas por interações sociais. Boaventura Santos diz que práticas sociais são práticas de saberes. Ao partir desse pressuposto, ele aponta que é possível - ao potencializar esses diferentes saberes - criar um paradigma emergente que possa emergir dele um pensamento alternativo às alternativas.

Em que pese que a forma epistemológica utilizada ao longo dos últimos três séculos tenha sido a ciência moderna, o progresso, o universalismo e a cultura global, ainda há déficits sociais que precisam ser resolvidos. Entende-se que estes existem porque o paradigma moderno se estabeleceu sobre bases que ao invés de priorizar as experiências do presente resolveram encurtá-lo em detrimento da expansão do futuro. A idéia de progresso se transformou na mola propulsora do crescimento econômico, no desenvolvimento da ciência e do mundo.

A perspectiva de que é sempre possível atingir novas metas e novos ideais, a ideia de que é no futuro onde se realizarão os grandes avanços, fez com que as pessoas renegassem as experiências do cotidiano em prol de expectativas criadas que poderão se concretizar quem sabe em um futuro bem distante, porque julga conhecê-lo. Ao fazer isso, a ciência moderna se responsabilizou em matar outras formas de saberes - alternativos - não reconhecendo a sua importância para a compreensão do mundo. Ao deixar de fora às experiências, ao desperdiçálas, a ciência moderna também se responsabilizou em gerar ausências e invisibilidades. (SANTOS, 2007).

A produção de ausências e emergências permite aumentar a quantidade de experiências sociais vivenciadas no interior de uma organização (SANTOS, 2006).

Acredita-se, portanto, que ao mapear as ausências e presenças inerentes às práticas de gestão será possível identificar não apenas o que é visível e passível de identificação nestas práticas, mas, aquilo que é produzido como não-existências pelas organizações.

\section{APRESENTAÇÃO E DISCUSSÃO DOS DADOS}

A luz dos dados, o que se coloca pelos docentes como invisível ou ausente é tudo aquilo que não é reconhecido ou praticado pelos gestores de universidades. No mesmo 
caminho, a produção de visibilidades ou presenças passa pelo reconhecimento dos direitos e saberes de todos os atores que constituem essas instituições.

Os dados da tabela 1 mostram as categorias que representam a produção de visibilidades e invisibilidades em universidades brasileiras e o lócus onde isso ocorre é nos espaços de gestão por meio de suas práticas.

Nesse sentido, a dignidade dos docentes, na maioria dos casos, especialmente, em algumas universidades particulares, não é reconhecida pelas instâncias decisórias o que em boa medida cria ou define limites que a determina.

Por outro lado, em outras universidades, as suas práticas de gestão estão orientadas para o reconhecimento dos saberes e direitos, e, portanto, para o reconhecimento da dignidade.

Tabela 1 Mapa das categorias visíveis e invisíveis refletidas nas práticas de gestão em universidades brasileiras.

\begin{tabular}{llll}
\hline Categorias invisíveis & $\begin{array}{l}\text { Natureza da } \\
\text { universidade }\end{array}$ & Categorias Visíveis & $\begin{array}{l}\text { Natureza da } \\
\text { universidade }\end{array}$ \\
\hline $\begin{array}{l}\text { Esclarecimento } \\
\text { Espaço para discussão } \\
\text { Transparência }\end{array}$ & $\begin{array}{l}\text { Ifes/Ipes } \\
\text { Ipes* }\end{array}$ & $\begin{array}{l}\text { Autonomia } \\
\text { Produtividade }\end{array}$ & $\begin{array}{l}\text { Ifes** } \\
\text { Ipes/Ifes }\end{array}$ \\
Ifes/Ipes & $\begin{array}{l}\text { Desenvolvimento } \\
\text { profissional }\end{array}$ & Ifes \\
Dignidade & Autonomia & Ifes \\
Respeito & Ipes & Lucratividade & Ipes \\
Autonomia & Ipes & $\begin{array}{l}\text { Desrespeito } \\
\text { Exploração }\end{array}$ & Ipes \\
& Ipes & $\begin{array}{l}\text { Dignidade } \\
\text { Precarização na relação de } \\
\text { trabalho }\end{array}$ & Ipes \\
& & Trabalho para garantia da \\
sobrevivência & Ipes \\
\hline
\end{tabular}

*Ipes - Instituição Privada de Ensino Superior

** Ifes - Instituição Federal de Ensino Superior

A tabela 1 apresenta as principais categorias apontadas pelos entrevistados, e, como se esperava, foi possível identificar a produção de ausências e emergências nas práticas de gestão em universidades brasileiras. As categorias esclarecimento e transparência foram apontadas como ausências nas práticas de gestão tanto em instituições públicas de ensino superior (Ifes) como nas instituições privadas de ensino superior (Ipes). A fala da docente que trabalha em uma universidade federal revela a falta de transparência e esclarecimento na gestão da universidade federal onde trabalha. 
"Primeiro um pouco mais de transparência, que eu acho que falta ali.(...) A gente sabe os recursos que foram, a gente sabe até onde está indo, sabe que parte desses recursos voltaram, mas não sabe onde eles estão sendo aplicados. Então, um pouco de transparência”.

“(...) E quando eu digo esclarecimento, é colocar, deixar as coisas um pouco mais transparentes, um pouco mais claras, onde é que realmente estão os problemas, por que as coisas não estão acontecendo. Eu não estou pedindo uma planilha não. Eu estou pedindo apenas informações".

A forma como ela se expressa mostra que enquanto trabalhadora, se vê como partícipe do processo de gestão, no entanto, no momento em que essas categorias não se refletem nas práticas de gestão da universidade elas se caracterizam como ausências produzidas por esta organização ao não enxergá-la como ator social que participa e que compreende todo o processo de gestão. Apesar de atuar na área da docência, as práticas de gestão, que em um primeiro momento, podem ser exclusivas de quem opera o management, via de regra, interferem nas suas próprias práticas.

Isso por sua vez reflete o modelo organizacional assentado em pressupostos onde o campo de decisão e o campo da ação estão separados. Ao professor cabe-lhe apenas o ofício de ministrar aulas e a gestão o domínio da "máquina".

A fala da docente de uma universidade privada revela também a falta de transparência como uma produção de ausência nas práticas de gestão e, nesse caso, pode-se inferir que os gestores agiram sem se preocupar com o ser humano que estava a serviço da organização.

\footnotetext{
"Mas digamos que você achasse que eu tinha responsabilidade em todas essas reclamações, me parece que a maneira correta era me chamar e dizer: '-Olha, professora, os alunos fizeram, lá, a avaliação e disseram isso, aquilo. O que você me diz? Por favor, averigue, veja o que está vendo, como é que a gente pode sanar.' Não. A ouvidoria mandou o relatório para você e você, ao invés de compartilhá-lo comigo, você mandou um recado por outro diretor que é um subalterno, um empregado, também, para dizer que, eu, a partir daquele momento, não era mais coordenadora. Você me desculpe, mas eu tenho um nome a zelar e eu nunca fui tão humilhada, tão ofendida." (P3)
}

Além da ausência de transparência percebeu-se que a prática de gestão dessa universidade não foi orientada para o respeito e consideração, e, por consequência, para o reconhecimento da dignidade do docente. Nesse sentido, pode-se dizer que estas são também categorias ausentes nas práticas sociais desta organização. Percebeu-se que as práticas de gestão dessa universidade refletem a precarização na relação de trabalho bem como evidencia a sua natureza produtivista e orientação para o mercado e para o cliente. Pode-se dizer que a partir do momento em que a organização percebe que o trabalhador não é produtivo ele é descartado. Essa ausência pode ser explicada por meio da monocultura da produtividade 
capitalista que parte da ideia de que a única coisa que conta é a produtividade em um ciclo de produção e tudo o mais não conta (SANTOS, 2007). Isso se revela na fala que segue:

"Eu vivi uma experiência, há pouco tempo, que me deixou um tanto magoada. A ideia de que a gente é totalmente descartável”. (P3)

A próxima citação revela que na organização onde trabalha - faculdade particular - as práticas de gestão promovem a precarização na relação de trabalho. Percebe-se que mesmo falando de uma organização de ensino superior prevalece a lógica produtivista e capitalista cujo relação de trabalho é orientada para a exploração do trabalhador. A partir do momento em que a docente afirma que tem que "ler a cartilha" da instituição privada, ela está submetida à práticas de gestão que não refletem dignidade e nem emancipação. $O$ relato aponta que ela se mostrou prisioneira da lógica produtivista. Há no relato sinais que podem indicar ausência de reconhecimento na dignidade do docente, principalmente quando assume que se faz necessário se submeter a uma realidade como aquela.

"Ou seja, é muito simples. Se você não lê a cartilha de uma instituição privada, você sai. Aí, a questão da sobrevivência, em alguns momentos, te leva a se submeter a uma realidade como aquela". (P10).

A fala de outra docente aponta também para as ausências refletidas nas práticas de gestão de uma universidade privada.

\footnotetext{
"Outra coisa que me causa muita impressão é essa precarização da relação trabalhista. Então, você é contratado para dar algumas turmas. Se no semestre seguinte não tiver turma, você está fora. Não importa: -Você tem que comer? Azar o seu. Você já devia ter aprendido a não comer".(P5).
}

Além de mostrar a precarização da relação de trabalho sinaliza ausência de dignidade e de respeito à pessoa humana. A submissão às regras estabelecidas pela universidade e a ausência de contratos demonstra que o docente vivencia uma relação de trabalho pautada pela insegurança e pelo não reconhecimento do direito ao trabalho. Para dar respostas às ausências produzidas pelas monoculturas, Boaventura Santos apresenta um conjunto de ecologias - de saberes, das temporalidades, do reconhecimento, da transescala e das produtividades. Segundo Santos $(2007 ; 2010)$, as ecologias pressupõe novas possibilidades, inclusive a de transformar as ausências em emergências.

Acreditar nessa possibilidade é crer que é possível se apropriar de outros saberes e credibilizá-los como alternativas que podem ou não seguir um caminho contra-hegemônico. 
No que se refere às práticas de gestão em universidades brasileiras se percebeu que estas, apesar de serem organizações voltadas para o ensino e para saberes, pouco refletiram em suas práticas de gestão: dignidade e respeito.

Foi possível observar que as práticas de gestão de universidades refletiram exploração, desrespeito, autonomia, segurança, formação profissional e a predisposição para a lucratividade. A fala de diferentes docentes mostra que a universidade privada tem uma forte predisposição para obtenção do lucro. Essa afirmação pode ser ratificada pelo pensamento de BSS quando ele aponta a monocultura do produtivismo capitalista.

\begin{abstract}
"Se você fizer um balanced scorecard de qualquer organização de ensino, você vai encontrar: reduzir custo, aumentar receita. Como é que se faz isso? Transformando o professor em operário". (P4)

"E aí, a lógica que se colocava na privada. (...) a lógica era a da produtividade, a lógica de quanto você fez, quanto você conseguiu atingir. Essa era a lógica que realmente emanava de lá". (P6).
\end{abstract}

É importante destacar a fala da docente quando diz que:

"Então, uma das coisas mais lindas da instituição federal é a segurança de que se você quiser fazer um bom trabalho, desde que você tenha essa paciência de correr os trâmites e se você entender o processo e não brigar com o processo, você pode fazer basicamente o que você quiser". (P3).

È possível identificar nesse relato que a Universidade a qual se referia, refletia em suas práticas de gestão a visibilidades dos docentes que ao que parece, a categoria autonomia pode ser utilizada para caracterizar essa visibilidade ou não-ausência. Foi possível identificar na fala da docente outra produção de visibilidade nas práticas de gestão de uma Universidade Federal.

"Espaço para o professor, em termos de pesquisa, em termos de qualificação. A universidade federal é digna nesse espaço". (P9)

“A gente tem mais autonomia. É outro elemento. A gente tem muito mais autonomia em uma instituição pública. Pelo menos é o que eu ando percebendo". (P8)

É oportuno evidenciar que enquanto autonomia e respeito foram categorias identificadas como ausências nas práticas de gestão em universidades privadas podem ser consideradas como visíveis em instituições federais de ensino superior.

Os limites da dignidade refletidas nas práticas de gestão em universidades puderam ser percebidos a partir da natureza da organização: se pública ou privada. Ao analisar as falas dos docentes de universidades privadas se observou que as práticas de gestão destas organizações 
não se diferem de qualquer outra que produz mercadorias, e, todavia, são orientadas pela cultura do gerencialismo e da produtividade.

Assim sendo, os trabalhadores (docentes) destas organizações que estão diretamente envolvidos em práticas acadêmicas que orientam e produzem saberes científicos, não tem a sua dignidade reconhecida por aqueles que gerenciam o seu trabalho. As falas dos docentes de universidades privadas colocam em discussão sobre como essas relações de trabalho, que produzem ausências, invisibilidades e o não reconhecimento de dignidade dos docentes, refletirão na formação humana e profissional daqueles que demandam seus serviços.

Se por um lado, as universidades privadas produzem ausências de autonomia, de soberania e de respeito dos docentes, em universidades públicas, a burocracia e a "politicagem" atuam no mesmo sentido, ou seja, produzem ausências de dignidade dos docentes no exercício de sua profissão.

“ [...] uma das coisas com as quais eu estava um pouco chateada era a dificuldade de se fazer qualquer coisa: tudo que tinha passar por não sei quantos colegiados e tal. E a política, que é muito boa, e a politicagem, que é muito ruim, estavam presentes". (P11)

Ao ter um modelo de gestão burocrático e também complexo, ele, via de regra, podem produzir ausências de dignidade de docentes a partir do momento em que não haja convergência de interesses dentro dos colegiados. Nesse sentido, a politicagem, pode ser incorporada como uma prática de gestão e que pode produzir invisibilidades e ausências de dignidade daqueles que porventura não se adequarem as regras do jogo.

“ [...] O grande problema é que, mesmo tendo o espaço da fala, em alguns momentos, essas falas não são, de fato, ouvidas. Assim como em qualquer outro ambiente de trabalho, você tem hierarquias etc e tal". (P6)

“[...] A questão de conchavos, antes de ir para uma reunião, para você passar uma ideia boa, você tem que tentar, ainda, convencer várias pessoas antes da reunião". (P12)

“ [...] uma instituição federal você sabe que se você passar pelos colegiados e, enfim, tiver paciência e disposição de cooptar os colegas, de apresentar, de convencer etc". (P11)

“ [...] É uma coisa muito complicada da forma como ela está sendo feita hoje. Para tudo tem eleição, todo mundo é igual e essa democracia eu não vejo isso com bons olhos $[\ldots]$ é que os próprios docentes não têm espírito de corpo [...] E se introduziu na política, na gestão, é uma politicagem muito medíocre. [...] Então, eleição para reitor, eleição para diretor de centro, eleição para chefe de departamento e eleição para o vereador do interior é a mesma coisa". (P8) 
“[...] Na administração pública você tem um aparato de colegiados, que leva, não tenho a menor dúvida, leva à ineficiência, a uma abordagem de natureza absolutamente política que apequena os colegiados". (P8)

O que se percebe é que em universidades públicas a produção de inexistências ou de ausências de dignidade de docentes ocorre por meio de práticas políticas que se cristalizam na gestão. Como é uma instituição pública os cargos de gestão são ocupados, via de regra, por docentes e técnicos eleitos pela comunidade e pelos seus pares, o que cria uma cultura organizacional orientada pelo corporativismo que também gera ausências de emancipação e dignidade de docentes.

\section{CONSIDERAÇÕES FINAIS}

O objetivo deste artigo consistiu em conhecer como as práticas de gestão mediadas por relações sociais em universidades brasileiras refletem emancipação e dignidade dos docentes.

Ao analisar o conteúdo das respostas dos entrevistados pode-se perceber que as práticas de gestão em universidades brasileiras pouco refletem emancipação/dignidade, tendo em vista que as categorias respeito, autonomia, transparência e precarização das relações de trabalho foram as principais categorias apontadas como ausentes, e, portanto, produzidas como invisibilidades a partir das práticas de gestão. O que chamou atenção foi perceber que as práticas de gestão de universidades além de refletir ausências, refletem também a produção de existências que são comuns em organizações produtoras de mercadorias tipicamente capitalistas. Outro ponto que merece ser destacado está relacionado as possíveis visibilidades refletidas nas práticas de gestão de universidades públicas. A partir dos dados é oportuno supor que como estas organizações não têm como objetivo a maximização de lucro, as relações sociais estabelecidas nas práticas de gestão apresenta um conteúdo substantivo que pode representar dignidade e emancipação.

A literatura que discute questões relacionadas a instituições de ensino superior aponta que no Brasil o fim último destas instituições de natureza privada é a obtenção de lucro (DIAS SOBRINHO, 2005; CHAUI, 2003). Nesse sentido, pode-se inferir que a lógica que prevalece é a produtivista tanto no que concerne a sua natureza organizativa quanto a sua natureza acadêmica - ensino, pesquisa e extensão -. Quanto as instituições públicas de ensino, a literatura evidencia que em nível mundial elas passam por crises de hegemonia, de legitimidade e institucional (SANTOS, 2005). Estas crises estão interligadas, porém as duas 
primeiras estão diretamente conectadas a última por razões de cunho organizacionais e de política de estado.

As instituições públicas de ensino superior ao se submeterem a lógica produtivista para alcançar objetivos e fins específicos de natureza capitalista, se assemelham as organizações produtivas que produzem bens e serviços. Assim, pode-se dizer que ao assumir essa condição suas práticas gerenciais tendem a refletir em menor intensidade os ideais humanísticos tão necessários a estas instituições.

Por fim, considerando a importância destas instituições para um país não apenas para produzir e difundir conhecimento para o mercado, mas, sobretudo, para contribuir para a formação humanística da sociedade é que se coloca como sugestão reavaliar e repensar as suas práticas de gestão, de modo que elas possam refletir dignidade/emancipação.

\section{REFERÊNCIAS BIBLIOGRÁFICAS}

AKTOUF,O. Administração e teorias das organizações contemporâneas: rumo a um humanismo radical crítico? Revista Organização e Sociedade (O\&S). Salvador, v.8, n.21, p. 13-33, Maio/Agos. 2001.

BOSSI, A. P. A precarização do trabalho docente nas instituições de ensino superior no Brasil nesses últimos 25 anos. Revista Educação e Sociedade. Campinas, vol. 28, n. 101, p. 150323, set./dez. 2007.

CARAN, V. C. S. et al. Assédio moral entre docentes de instituição pública de ensino superior do Brasil. Acta Paul. Enferm. [online]. v. 23, n. 6, p. 737-44, 2010.

CHAUI, M. A universidade pública sob nova perspectiva. Revista Brasileira de educação, n. 24, set. /out. /nov. /dez. 2003.

DIAS SOBRINHO, J. Educação superior, globalização e democratização. Qual universidade? Revista brasileira de educação, n. 28, jan /fev /mar /abr, 2005.

FREITAS, M. E. Assedio moral e assedio sexual: faces do poder perverso nas organizações. Revista de administração de empresas - RAE -. São Paulo. Vol. 41, no. 2, p. , Apr./June2001.

HELOANI, R. Assédio Moral - um ensaio sobre a expropriação da dignidade no trabalho. RAE-eletrônica, v. 3, n. 1, jan./jun. 2004.

LEDA, D. B. Trabalho docente no ensino superior sob o contexto das relações sociais capitalistas. In: Reunião anual da associação nacional de pós-graduação e pesquisa em educação - ANPED, 29., 2006, Caxambu. Anais... Caxambu: ANPED, 2006. 
MARGOLIS, J.D. Dignity in the balance: philosophical and pratical dimensions of promoting ethics in organizations. 1997. Tese (Doutorado) . Cambridge: Harvard University, 1997.

MOTTA, F.C.P. As empresas e a transmissão da ideologia. Revista de administração de empresas - RAE. São Paulo, v.24, n 3, p.19-34, jul/set. 1984.

SOUSA SANTOS, B. A gramática do tempo: uma nova cultura política. 3 ed. São Paulo: Cortez, 2010a. (coleção para um novo senso comum; v. 4).

.Um ocidente não-ocidentalista? A filosofia à venda, a douta ignorância e a aposta de pascal. In:__ MENESES, M. P (Orgs.). Epistemologias do Sul. São Paulo: Cortez, 2010 b.

.A Universidade no século XXI: Para uma Reforma Democrática e Emancipatória da Universidade. Educação, Sociedade \& Culturas, n. 23, p. 2010c.

Um discurso sobre as ciências. 7 ed. Porto: Edições afrontamento, 2009 b.

.A crítica da razão indolente: contra o desperdício da experiência. 7 ed. São Paulo: Cortez, 2009a. (coleção para um novo senso comum; v.1). 2007.

.Renovar a teoria crítica e reinventar a emancipação social. São Paulo: Boitempo,

Para além do pensamento abissal: das linhas globais a uma ecologia de saberes.

Novos Estudos, n. 79, 2007.

.Conhecimento prudente para uma vida decente: "um discurso sobre as ciências" revisitado. 2 ed. São Paulo: Cortez, 2006.

.Os processos da globalização In: (Org.) Globalização: Fatalidade ou utopia? 3 ed. Porto - PT: edições afrontamento, 2005b.

.Pela mão de Alice: o social e o político na pós-modernidade. 10 ed. São Paulo: Cortez, 2005a.

. (Org). Reconhecer para libertar: os caminhos do cosmopolitismo multicultural. Porto: PT. Edições afrontamento, 2004.

. Seis razões para pensar. Lua Nova, n. 54, 2001. junho, 1991.

Subjetividade, cidadania e emancipação. Revista crítica de ciências sociais, n. 32 , Introdução a uma ciência pós-moderna. 5 impre. Rio de Janeiro: Graal, 1989. 
Junho, 1978.

Da sociologia da ciência a política cientifica. Revista crítica de ciências sociais, n.1,

TEIXEIRA, M. L. M. Dignidade Organizacional: valores e relações com stakeholders.

In: (Org.). Valores humanos e gestão: novas perspectivas. São Paulo: Senac, 2008. p. 81-92.

TRÉPO, G.X. Qual deve ser a atitude do executivo diante dos modismos na administração? Revista de administração de empresas (RAE).São Paulo, v. 34, n. 4, p. 93-97, jul/ago, 1994. 